\title{
An Evacuation Model for Use in Fire Safety Design of Buildings
}

\author{
KIYOSHI TAKAHASHI \\ Fujita Corporation \\ 4-6-15 Sendagaya \\ Sibuya-ku, Tokyo 151, Japan
}

\author{
TAKEYOSHI TANAKA and SATOSHI KOSE \\ Building Research Institute \\ Ministry of Construction \\ 1 Tatehara, Tsukuba-shi \\ Ibaraki 305, Japan
}

\section{ABSTRACT}

An evacuation model was developed in a research project of the Ministry of Construction: "Development of Fire Safety Design Method of Buildings". The model is to be used as a tool for an evacuation design. It is to predict and evaluate evacuation time of people in a fire. The scope of application of the model is restricted only to the evacuation of low level hazard. This is a kind of network model and assumes that evacuees move like a fluid. The predicted results using the model is compared with the observed egress time by field measurements of Tsukuba Int'1 Expo'85. The comparison showed that they were in good agreement. Consequently, this evacuation model can be used as a reasonable tool for design purposes. Also, a method was developed for visual presentation of the predicted evacuation behavior by personal computer graphics.

\section{INTRODUCTION}

To date, fire safety measures of buildings in Japan have been determined almost always according to the specification standards of The Building Standard Law of Japan. However, it is necessary to replace these specification standards with performance ones as much as possible for the rationalization of both fire safety performance and cost and for more flexible design of buildings. In recognition of this need, Building Research Institute (BRI) has carried out a research project "Development of Fire Safety Design Method of Buildings" with the participation of researchers and designers of universities and private construction companies. To introduce performance standards into a fire safety design method, many kinds of prediction methods are indispensable for evaluating various aspects of fire behavior. An attempt was made to develop a computer model of evacuation by FoRTRAN. This paper outlines the theory of the model and demonstrates its predicting capability by means of comparison with the data of field measurements conducted during Tsukuba Int'1 Expo'85 (Ref.1).

EVACUATTON MODEL,

Scope of The Model

Many evacuation models have been developed up to now to evaluate human behavior in a fire. One of the directions of the developments is to try to 
predict or explain human behavior in really hazardous conditions in a fire by means of introducing models of human reactions to fire or smoke. Those models may be interesting as a basic tool or as an attempt to interpret human behavior in a fire, but it is too ambitious to use this type of model for fire safety design purposes because human behavior in a fire will vary from one individual to another. There is virtually no reasonable means to validate human reaction models to fire conditions at present, and it will require too much time and too many runs until the fire safety design of a building is decided because this type of models is sensitive to fire conditions and give different answers under different fire scenarios, including location of the room of fire origin, behavior of smoke movement.

On the other hand, if the scope of application of a model is restricted only to design purposes, the model does not necessarily have to be very sophisticated. In an evacuation design, if prediction of evacuation is possible only when the hazard level to evacuees is not too high, a building should be so designed that the necessary level of safety will be attained during the period of evacuation, by means of compartmentation, smoke control and so on. The present model was developed according to the above consideration and adopts basic premises as follows:

1. Necessary safety level is maintained throughout the route during the period of evacuation that orderly evacuation can be carried out.

2. The evacuation plan is adequate enough to realize in actual fire situations.

Modeling of Building Spaces

Building spaces are modeled as an evacuation space system composed of six kinds of space elements (room, path, stair, vestibule, hall and refuge) and two imaginary spaces (link and crowding) are shown in Fig.1. The latter two are introduced to make the concept of the calculation procedure clear.

Modeling of Evacuees' Movements

Evacuees. It is assumed that the evacuees are homogeneous in evacuation abjlity and move like a fluid with a constant speed in each space element.

Initial distribution of evacuees. It is assumed that the evacuees are uniformly distributed in rooms (Ref.2).

Starting time of evacuation. In actual fires, it is not unusual that

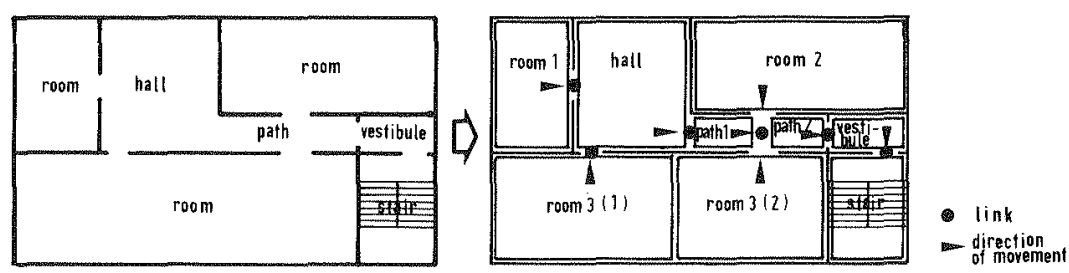

FIGURE 1. An example of modeling of building spaces 
the evacuation starts significantly after the onset of fire, and this delay time can never be neglected in the total evacuation time. It is not however easy to assess the starting time of evacuation because this depends on various conditions such as nature of occupants, fire detection and alarm systems, guiding method of evacuees and building spaces. A certain delay time is assumed in this model, which is given as input data.

Movement of evacuees in rooms (L-shape approach to exit). As was stated before, when a room has multiple exits, the roon is further divided into room units each of which corresponds to an exit as is shown in Fig. 2 . The evacuees in a room unit, who are distributed uniformly at the initial. point of. time, start to move toward the exit simultaneously. Two types of approach to an exit are considered. In such rooms as large offices, where much office furniture usually exists, it will be difficult for evacuees to approach to an exit directly. Hence, in such a case, it is assumed that evacuees take an L-shape approach to an exit. Consider first the case where the exit is located at a conner of a room. The evacuees who arrive at the exit from the start by a certain lapse time $t$ are those who were initially within the L-shape distance $v \cdot t$, those in the shaded area in Fig. 3 .

In mathematical form, the number of evacuees is given as follows:

$$
P= \begin{cases}\rho \frac{(v t)^{2}}{2} & \left(0<t \leq \frac{a}{v}\right) \\ \rho\left\{\frac{a^{2}}{2}+a(v t-a)\right\} & \left(\frac{a}{v}<t \leq \frac{b}{v}\right) \\ \rho\left\{a b-\frac{(a+b-v t)^{2}}{2}\right\} & \left(\frac{b}{v}<t \leq \frac{a+b}{v}\right)\end{cases}
$$

where a : length of shorter side of the room (m)

$\mathrm{b}$ : length of longer side of the room (m)

$t$ : lapse time from the start (sec)

$\mathrm{v}$ : walking speed ( $\mathrm{m} / \mathrm{sec}$ )

$\rho$ : density of evacuees (person $/ \mathrm{m}^{2}$ )

$\mathrm{P}$ : number of evacuees arriving at the exit by time $t$ (person)

Whether the evacuees take a literal I-shape course with one turn or take

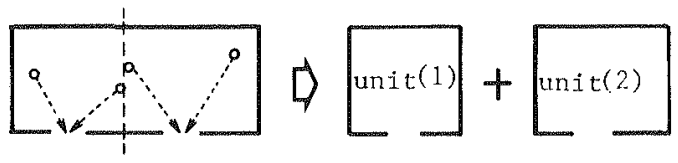

FIGURE 2. Division of a room into room units
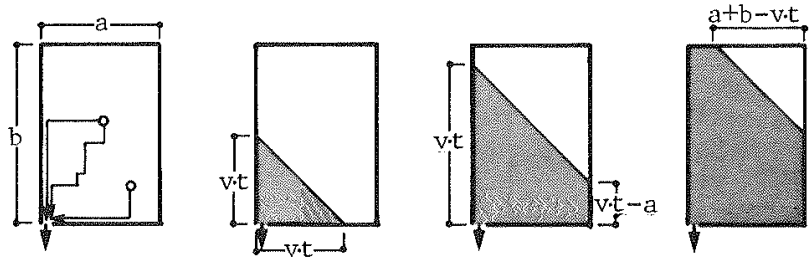

FIGURE 3. The number of evacuees arriving at the exit within time $t$ 
a course with several turns does not make difference in the distance to an exit unless they go backward. The extra time that might arise during an L-turn was ignored because it was suggested as negligible (Ref.3).

(Centripetal approach to exit). In rooms with few obstacles for walking, such as assembly rooms without fixed seats, party rooms and gymnasiums, it is reasonable to assume that evacuees make centripetal approach to the exit. In this case, referring to Fig.4, the number of evacuees arriving at an exit is given as follows:

$$
P= \begin{cases}\rho \frac{\pi(v t)^{2}}{4} & \left(0<t \leq \frac{a}{v}\right) \\ \rho\left\{\frac{(a v t) \sin \theta_{1}}{2}+(v t)^{2} \frac{\left(\pi / 2-\theta_{1}\right)}{2}\right\} & \left(\frac{a}{v}<t \leq \frac{b}{v}\right) \\ \rho\left\{\frac{(a v t) \operatorname{SIN} \theta_{1}}{2}+(v t)^{2} \frac{\left(\pi / 2-\theta_{1}-\theta_{2}\right)}{2}+\frac{(b v t) \sin \theta_{2}}{2}\right\} & \left(\frac{b}{v}<t \leq \frac{\sqrt{a^{2}+b^{2}}}{v}\right)\end{cases}
$$

$$
\theta_{1}=\cos ^{-1}\left(\frac{a}{v t}\right), \theta_{2}=\cos ^{-1}\left(\frac{b}{v t}\right)
$$

The exit of a room unit is not always located at a corner, but as is seen in Fig.5, a room unit can be regarded as a combination of the two parts with an exit at a corner. So, the number of evacuees arriving at the exit can be calculated as a sum of the numbers of the evacuees of the two parts.

(Movement between crowdings). Since evacuees try to escape from fire hazards as fast as possible, it is reasonable to assume that in a room with multiple exits, they choose the exit through wich they are likely to make fastest egress from the room. As a result, the numbers of the crowdings at the exits of a room are redistributed to minimize the expected time of the dissolution of al1 the crowdings of the exits. Because the expected minimum time for the dissolution of all the crowdings is

$\operatorname{Tmin}=\frac{\sum \mathrm{Cc}(i)}{\sum \text { Pout }(i)}$

when the egress at each exit continues at the rate of Pout(i), the optinal
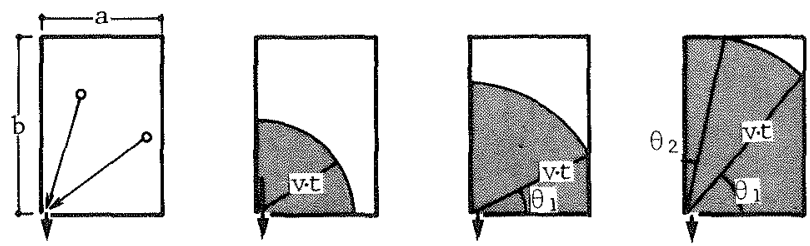

FIGURE 4. The number of evacuees arriving at the exit within time $t$
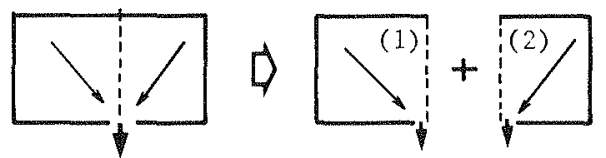

FIGURE 5. Division of a room unit into two parts 
redistribution of each crowding is given by

$\operatorname{Cr}(i)=\operatorname{Pout}(i) \cdot \operatorname{Tmin}$

where Pout(i) : egress rate at exit $i$ (person/sec)

$\mathrm{Cc}(i)$ : number of crowdings at exit $i$ before redistribution (person)

$\mathrm{Cr}(i)$ : number of crowdings at exit $i$ after redistribution (person)

Note that Pout(i) may change with time, as the condition of the space outside exit i changes.

Movement of evacuees in paths, stairs and vestibules. In this model, evacuees entering a space element are assumed to proceed orderly toward the exit without passing over or going backward. Since paths, stairs and vestibules are divided into units with the length that can be cleared at time increment $v \cdot \Delta t$, the evacuees in a space unit move forward to the next unit at every time step (Fig.6).

Movement of evcuees in halls. Consider a general case where a hall is crowded with evacuees and crowdings are formed at exits (Fig.7). The evacuees entering a hall at such conditions are assumed to pick up the exit so as to minimize the egress time taking into account of the crowdings at the exits, the numbers of evacuees approaching to the exits, the distance to the exits and the rate of egress at the exits. Let $P$ be the number of evacuees entering through an entrance during the period of time $\Delta t$. If the numbers of evacuees are allotted optimally so that the egress time from the hall becomes minimum, the egress times at all exits must be the same, that is

$$
\begin{gathered}
\operatorname{Tmin}=t(1)+\frac{\mathrm{Cp}(1)+P(1)}{R(1)}=t(2)+\frac{C p(2)+P(2)}{R(2)}=\cdots \\
\cdots=t(i)+\frac{C p(i)+P(i)}{R(i)}=\cdots \\
C p(i)=\left\{\begin{array}{l}
C c(i)+W(i)-R(i) \cdot t(i) r \\
0 \quad(C c(i)+W(i)>R(i) \cdot t(i))
\end{array}\right.
\end{gathered}
$$

where $t(i)$ : time to arrive at exit i (sec)

$P(i)$ : number of evacuees allotted to exit $i$ (person)

R(i) : egress rate at exit i (person/sec)

Cc(i) : number of evacuees in the crowding at exit 1 (person)

$W(1)$ : total number of evacuees arriving at exit $i$ from the entrance within time $t(i)$ (person)

$i$ : exit number in order of the magnitude of $t(i)+C_{p}(i) / R(i)$

From Eqn. (5), Tmin is given by

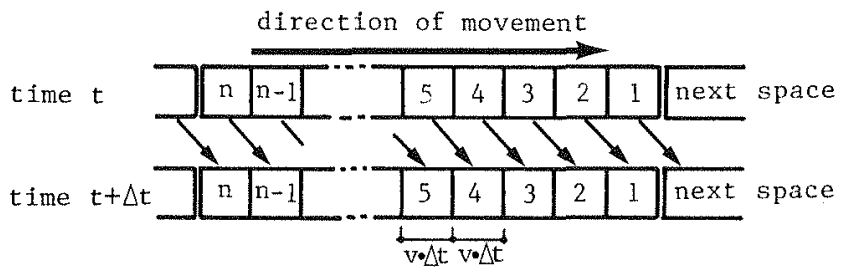

FIGURE 6. Movement in paths, stairs and vestibules 


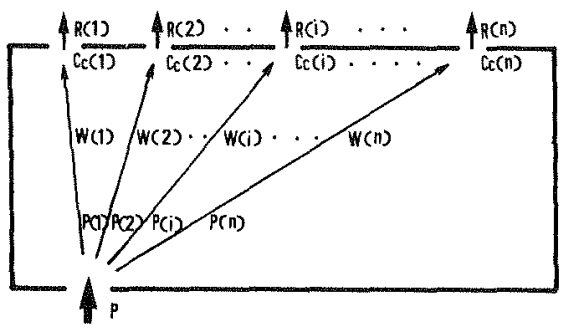

FIGURE 7. Exit selection in a hall

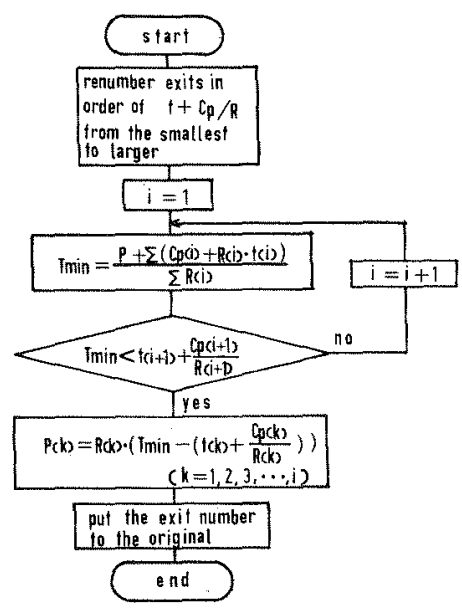

FIGURE 8. Procedure to yield Tmin and $P(i)$ in a hall

$\operatorname{Tmin}=\frac{\sum(R(i) \cdot t(i)+C p(i)+P(i))}{\sum R(i)}=\frac{p+\sum\left(R(i) \cdot t(i)+C_{p}(i)\right)}{\sum R(i)}$

So, it follows that the optimal allotment of evacuees is given by

$P(i)=R(i) \cdot\left\{\operatorname{Tmin}-\left(t(i)+\frac{C_{p}(i)}{R(i)}\right)\right\} \quad(i=1,2, \cdots, n)$

where $\mathrm{n}$ is the number of exits. However, this problem is not so simple because the optimal solution is not always obtained when all exits are used. If all. the evacuees choose the nearest exit, the egress time will be

$T=t(1)+\frac{C p(1)+P(1)}{R(1)}$

So, iff $T<t(2)+C p(2) / R(2)$, the evacuees can go out of the hall faster when they choose only one exit $(i=1)$ rather than when they choose the others. Therefore, the optimal time Tmin and allotment $P(i)$ have to be calculated according to the procedure described in Fig.8 (Ref.4).

Movement of evacuees through a link (Total number of evacuees moving through a link). Movement of evacuees from a space element to another is treated by the concept of movement through a link. The number of evacuees who move through interface of space elements cannot be simply determined because it depends on the number of evacuees ready to move, the available capacity of the space to move into, the width of the openings and the number of space elements combined. Links are introduced to deal with this complex movement around the connecting parts of the spaces. Consider a general case where multiple space elements from which evacuees come out are combined with multiple space elements to which they move into. A link is assumed between the former and the latter as is shown in Fig.9. Suppose that during a time step $\Delta t$, movement of evacuees takes place in each space element and evacuees have been added to the crowdings of the space elements in the upstream of the link and empty spaces have appeared in the downstream spaces. In this case, the number of evacuees which can be allowed in a downstream spaces is determined either by the available space or flow capacity of the entrance, that is 


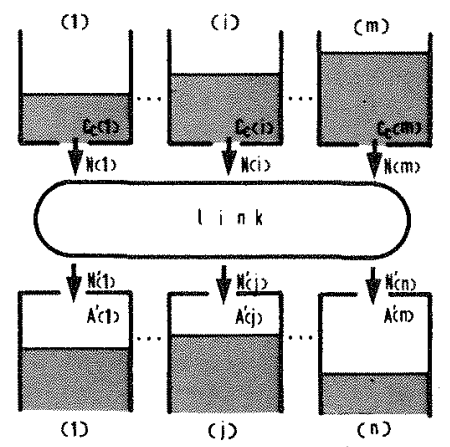

FIGURE 9. A link combining multiple space elements

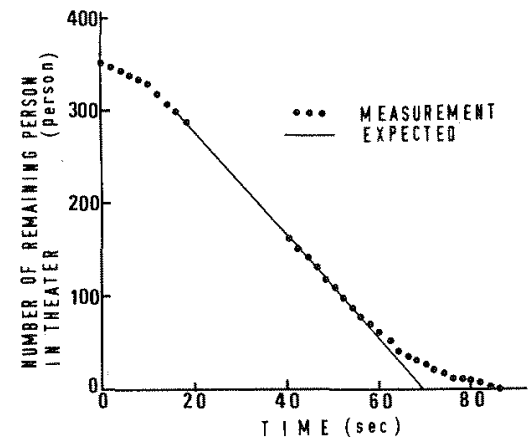

FIGURE 10. Typical tendency of egress from theater

$P^{\prime} \max (j)=M I N\left(N^{\prime}(j) \cdot \Delta t, p \max \cdot A^{\prime}(j)\right)$

where $N^{\prime}(j)$ : flow capacity of entrance of space element $j$ (person/sec)

$A^{\prime}(j)$ : space available in space element $j\left(\mathrm{~m}^{2}\right)$

$0 \max :$ maximum density of evacuees (person $/ \mathrm{m}^{2}$ )

The total number of evacuees allowed in the downstream spaces $\sum$ P'max $(j)$ becomes

$\sum P^{\prime} \max (j)=\sum M I N\left(N^{\prime}(j) \cdot \Delta t, \rho \max \cdot A^{\prime}(j)\right)$

On the other hand, the maximum number of evacuees who can egress from an upstrean space element is determined either by the number of evacuees waiting to egress, or by the egress capacity of the exit,

$\operatorname{Pmax}(i)=\operatorname{MrN}\left(\mathbb{N}(i) \cdot \Delta t, C_{C}(i)\right)$

$\sum P \max (i)=\sum \operatorname{MIN}(N(i) \cdot \Delta t, C c(i))$

where $C_{C}(i)$ is the number of evacuees in the crowding of space element $i$. Finally, actual number of evacuees PL who move through the link is given by:

$P L=\operatorname{MIN}\left(\sum \operatorname{MTN}(N(i) \cdot \Delta t, C c(i)), \sum \operatorname{MIN}\left(N^{\prime}(j) \cdot \Delta t, \rho \max \cdot A^{\prime}(j)\right)\right.$

(Allotment of evacuees to each path). Now that the total number of evacuees moving from one side to the other is decided, the number moving from a certain upstream space element to a certain downstream space element has to be determined. The number of evacuees coming out from space element $i$ :Pout( $i)$, and the number going into space element $j: P i n(j)$ are expressed as follows:

$\operatorname{Pout}(i)=\beta(i) \cdot P L, \operatorname{Pin}(j)=\beta^{\prime}(j) \cdot P L$

where $\beta(i)$ and $\beta^{\prime}(j)$ are the ratio of evacuees allotted to upstream space element $i$ and downstream space element $j$, and $\beta(j)$ and $\beta^{\prime}(j)$ are assumed to be proportional to $P \max (i)$ and $P^{\prime} \max (j)$ respectively. Needless to say

$\Sigma \beta(i)=1$ and $\Sigma B^{\prime}(j)=1$. Hence, 


$$
\begin{aligned}
& \beta(i)=\frac{P \max (i)}{\sum \operatorname{Pmax}(i)}=\frac{\operatorname{MIN}(N(i) \cdot \Delta t, C c(i))}{\sum \operatorname{MIN}\left(N(i) \cdot \Delta t, C_{C}(i)\right)} \\
& B^{\prime}(j)=\frac{P_{\max }^{\prime}(j)}{\sum P_{\max (j)}}=\frac{\operatorname{MIN}\left(N^{\prime}(j) \cdot \Delta t, \rho \max \cdot A^{\prime}(j)\right)}{\sum \operatorname{MIN}\left(N^{\prime}(j) \cdot \Delta t, \rho \max \cdot A^{\prime}(j)\right)}
\end{aligned}
$$

\section{COMPARISONS BETWEEN FIELD MEASUREMENTS AND PREDICTION}

The predicting capability of the evacuation model was demonstrated by means of the comparisons with the data obtained during field measurements of the egress behavior of the audience, evacuation drills at high-rise buildings and so on (Ref.1). The following is given as a sample of the comparisons between predictions and field measurements.

Measured Egress Time of the Audience from Tsukuba Int'1 Expo'85 Pavilions

Data obtained during field measurements of the egress behavior of the audience of seven pavilions of Tsukuta International Exposition were used for comparison. The results of the time of egress completion are given in Table 1. A typical characteristic egress is shown in Fig.10. The number of audience remaining in the theater counted from the video recordings is plotted as a function of time but the counting was only possible for the initial and the final parts of egress. For the main parts in between, a simple interpolation is adopted. In the final part, some of the audience walked leisurely and the egress completion was delayed by talling. If the tafling is cut off by extrapolating the slope of the main part, the egress time is $10-30$ sec shorter. These results are also given in Table $1(\operatorname{Ref} .5,6)$.

Prediction of Egress Time

The egress time of the audience from the theaters were calculated using the evacuation model. Two cases were considered for each theater, i.e:

\begin{tabular}{|c|c|c|c|c|c|c|c|c|c|}
\hline \multirow{3}{*}{ No. } & \multirow{3}{*}{$\begin{array}{l}\text { CODE } \\
\text { WAME }\end{array}$} & \multirow{3}{*}{$\begin{array}{l}\text { HUMBER } \\
\text { OF STAIBS }\end{array}$} & \multirow{3}{*}{$\begin{array}{l}\text { THEATER } \\
\text { FLOR } \\
\text { AREA } \\
\text { (ADL) }\end{array}$} & \multicolumn{2}{|l|}{ E X IT } & \multicolumn{3}{|c|}{ EGRESS COMPLETIOH TIME (SEC) } & \multirow{3}{*}{ NOTE } \\
\hline & & & & \multirow{2}{*}{$\begin{array}{l}\text { ToIAL WIOTH } \\
\text { (m) numbers } \\
\text { (mix number }\end{array}$} & \multirow{2}{*}{ DIRECIIOH } & \multirow{2}{*}{ MEASUREMENT } & \multirow{2}{*}{$\left(\begin{array}{l}\text { failing } \\
\text { cut off }\end{array}\right)$} & \multirow{2}{*}{\begin{tabular}{|l|} 
CALCULATLOA \\
casecas) casec b
\end{tabular}} & \\
\hline & & & & & & & & & \\
\hline 1 & SU & 424 & 540 & $(6.6 \times 1 \cdot 2.2 \times 1)$ & $R(F), R(B)$ & $61,71,75,60,64$ & $50-61$ & \begin{tabular}{l|l|}
52 & 62 \\
\end{tabular} & \\
\hline 2 & $\mathrm{FR}$ & 1000 & 1014 & $\begin{array}{c}5.1 \\
(5.1 \times 1)\end{array}$ & $L$ & $174,154^{* 1}$ & $125-155$ & $137: 275$ & \\
\hline 3 & TO & 508 & 693 & $\begin{array}{c}6.8 \\
(1.7 \times 4)\end{array}$ & B & $71,80,77,78,79$ & $60-77$ & $\begin{array}{l:l}50 & 76\end{array}$ & \\
\hline 4 & ST & 366 & 315 & $\begin{array}{c}4.0 \\
(2.0 \times 2)\end{array}$ & B & $94,111,102^{* 1}$ & $88-104$ & $\begin{array}{l:l}72 & 89\end{array}$ & \\
\hline 5 & NT & 350 & 452 & $\begin{array}{c}7.0 \\
(1.4 \times 5)\end{array}$ & $L$ & $70^{* 1} 123^{* 2} 84,77$ & $60-73$ & $\begin{array}{l:l}34 & 59\end{array}$ & \\
\hline 6 & $\mathrm{SH}$ & 500 & 563 & $\begin{array}{l}3.6 \\
(3.6 \times 1)\end{array}$ & $F(R)$ & $160,152,166,157$ & $140-150$ & $100 ! 107$ & on a rainy day \\
\hline 7 & TD & 405 & 401 & $\begin{array}{c}5.4 \\
(5.4 \times 1)\end{array}$ & $L(F)$ & 148. $118,130,121,131$ & $95-135$ & $70 !$ & on a rainy day \\
\hline
\end{tabular}

TABLE 1. Results of measurements and predictions of egress completion time 
case(a) in which simple L-shape approach to exits is assumed in the theater space, and case(b) in which the theater is composed of space units such as rooms and paths. In the latter, the walking speed at horizontal paths and stairs are taken as $1.0 \mathrm{~m} / \mathrm{s}$ and $0.5 \mathrm{~m} / \mathrm{s}$, respectively, and in the former, 0.7 $\mathrm{m} / \mathrm{s}$ was employed as the average walking speed considering that the space consists of horizontal paths and stairs. In both cases, the egress coefficients of exits on horizontal floor and on stairs are taken as 1.5 person $/(\mathrm{m} \cdot \mathrm{s})$ and 1.3 person $/(\mathrm{m} \cdot \mathrm{s})$, respectively (Ref.7).

The results of the prediction are also given in Table 1 . As can be seen, the predicted egress times of case(b) are consistently longer than case(a). This means that in the prediction for case(b), crowdings are formed in some parts within seating area of the theater. In fact, crowdings were observed along the aisles in many of the theaters during the field measurement.

Comparison between Prediction and the Measurement

It can be seen in Table 1 that the predicted egress times are generally shorter than measured ones and the predictions assuming case(b) give better agreement with the measurement except for $\mathrm{FR}$ pavilion. So, it is more appropriate to model a theater space as a combination of space units than to simply consider a room with L-shape approach in most of the theaters, because crowdings will. be usually formed along aisles. On the other hand, in FR pavilion, where the seats were low bench type ones and people could move freely over the seats, the calculation assuming case(a) gave a better prediction.

There are some other reasons why the measured egress times are longer than the predictions. Needless to say, the theaters are not in emergent conditions, and people walked out more or less leisurely in every case. In case of SH and TD pavilions, it was rainy on the day of the measurement, so the people stopped outside the exits to prepare rain outfits and delayed the egress of the remaining people. In NT pavilion, people on the upper floor went down through the same stair beside the theater and merged with the people from the theater.

Taking these factors into consideration, the present model is reasonable as a prediction tool to evaluate evacuation time for fire safety design of buildings.

\section{VISUAL PRESENTATION OF THE PREDICTED EVACUATION BEHAVIOR}

A visual presentation by personal computer graphics of the predicted evacuation behavior was developed as an application of this model. The predicted result in the building space in Fig.1 is shown in photo 1 . The number of evacuees in each space element is shown with five levels of density. The number of evacuees in each space element is shown, and especially for the crowding, the area of crowding occupied by evacuees is clearly visible.

\section{CONCLUSION}

Evacuation model developed here gave results that are in good agreement with the observed data. The model does not predict movement behavior of each 
Individual but estimate general movement pattern. It is however appropriate enough to check basic characteristics of evacuation design of buildings, and can be used as a tool for prediction. Graphic presentation technique of movement of evacuees developed at the same time has also proved to be effective in demonstrating appropriateness (or inappropriateness) of the evacuation design.

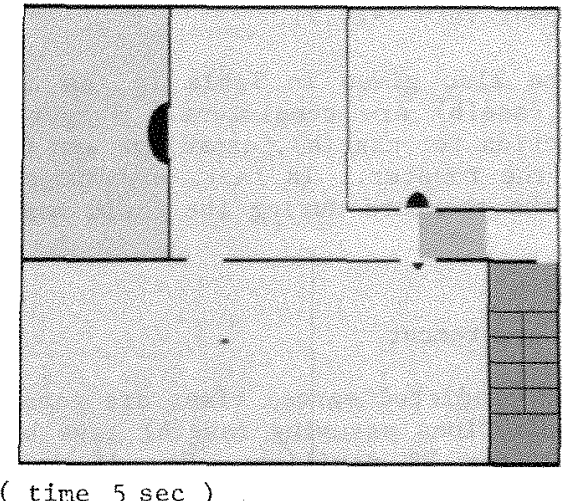

PHOTO 1. Visual presentation of the predicted evacuation behavior

\section{REFERENCES}

1. K. Takahashi and T.Tanaka, "An Evacuation Model for The Use in Fire Safety Designing of Buildings" 9 th UJNR Joint Pane1 Meeting on Fire Safety, Boston, 1986.

2. Yoshiyuk1 Yoshida, "Hinan keisan (Standard for Evacuation Calculation)" in Shin Kenchiku Bosai Keikaku Shishin-1985 (New Architectural Fire Safety Guideline-1985), edited by the Ministry of Construction, pp.123-142, Building Center of Japan, Tokyo, 1985.

3. V.M.Predtechenskit and A.I.Milinskii, Planning for Foot Traffic Flow in Bujldings, translated from Russian, p. 122, Published for the National Bureau of Standards, TT75-52054, Amerind Publishing Co. Pvt. Ltd., New Delhi, 1978.

4. K.Takahashi and T. Tanaka, "Prediction of The Evacuation Behavior in Space with Multiple Openings" Annual Meeting Reports of Fire Science and Engineering, pp.143-146, 1987.

5. K.Takahashi, T.Tanaka, T.Yamana and K.Nakamura, "Field Measurements of The Egress Behavior at Tsukuba Expo. Pavilions" Summaries of Technical Papers on Annual Meeting of Architectural Institute of Japan, Fire Division, pp.831-832, 1987 .

6. S.Kose, T.Tanaka, Y.Morishita, M.Kagawa, K. Kato and K.Takahashi, "Analysis of exit movement of people out of theater--Comparison of observation and computer simulation-m", in Proceeding of CIB 86, pp.2885-2892, 1986 .

7. Kikuji Togawa, Study on Fire Escapes basing on the Observations of Multitude Current, Report of the Building Research Institute No.14, 1955. 